\title{
Medical Talc Pleurodesis: Which Patient with Cancer Benefits Least?
}

Aldona Wajda, Helena Engstrom and Lennart Persson

\section{Linköping University Post Print}

\section{Tweet}

N.B.: When citing this work, cite the original article.

Original Publication:

Aldona Wajda, Helena Engstrom and Lennart Persson, Medical Talc Pleurodesis: Which Patient with Cancer Benefits Least?, 2014, Journal of Palliative Medicine, (17), 7, 822-828. http://dx.doi.org/10.1089/jpm.2013.0591

Copyright: Mary Ann Liebert http://www.liebertpub.com/

Postprint available at: Linköping University Electronic Press

http://urn.kb.se/resolve?urn=urn:nbn:se:liu:diva-109389 


\title{
Medical Talc Pleurodesis: Which Patient with Cancer Benefits Least?
}

\author{
Aldona Wajda, MD, Helena Engström, MD, and H. Lennart Persson, MD, PhD
}

\begin{abstract}
Background and Objective: Successful talc pleurodesis (TP) for malignant pleural effusion (MPE) gives symptom relief, but may be too exhaustive in cases with poor performance status. The selection of eligible patients is therefore a challenging task. The study was undertaken to evaluate frequency of successful TPs, side effects, complications, performance status, hospitalization time, remaining time alive, and the responsible physician's prediction of a successful TP judged by radiologic findings prior to TP.

Methods: Side effects of TPs performed during a 1-year period were consecutively recorded and the TP outcomes were retrospectively evaluated 6 years later.

Results: TP success rate was $56 \%$ and $79 \%$ among best support of care subjects (BSC; $n=10$ ) and subjects eligible for cancer therapy (non-BSC; $n=19$ ), respectively, while side effects did not differ. Performance status was poorer and survival shorter among BSC subjects. Time spent in hospital of the remaining time alive for BSC and non-BSC subjects was $42 \% \pm 27 \%$ and $4 \% \pm 4 \%$, respectively. Poor performance status of subjects with lung cancer correlated with short survival time, which in turn correlated with many days at hospital for TP. The physician's prediction of a successful TP was correct in $50 \%$ of all cases.

Conclusions: Performance status of BSC subjects are probably too poor for TP and these subjects have to spend too much time at hospital during the procedure. The responsible physician is able to correctly predict a successful TP outcome in only every second case, supporting the need of additional predictive analysis.
\end{abstract}

\section{Introduction}

M ALIGNANT PLEURAL EFFUSION (MPE) often causes disabling breathlessness. ${ }^{1-6}$ Pleurodesis, using talc administered bedside as a slurry (TP), is the first-line therapeutic approach for patients presenting with symptomatic MPE. ${ }^{1-3,7-9}$ MPE may be a sign of advanced end-stage disease associated with a poor prognosis (expected survival less than 3 months). ${ }^{2,10}$ Such patients account for more than onethird of all MPE cases. ${ }^{11}$ For these patients TP is used as a part of the best support of care (BSC) management. ${ }^{1,2}$ However, many TP-treated patients have longer life expectancy (3 months or more) because of treatments that still are available. ${ }^{2,6,10-14}$ In these cases TP is performed to improve conditions prior to planned cancer therapy, i.e., chemotherapy and/or radiation.

The estimated chance for successful TP should be accounted for before a decision is made to proceed to TP. Some researchers favor a variety of analyses on the pleural fluid, ${ }^{15,16}$ but in clinical practice expected TP success is usually based solely upon clinical and radiologic findings presented to an experienced pulmonologist. Thus, TP is not suitable in cases of very poor performance status (performance status 4 according to $\mathrm{WHO}^{17}$ ), i.e., patients completely disabled and therefore confined to bed or chair, 2,6,10,15 and cases of trapped lung, thus, when the visceral and parietal pleural layers are apart after the fluid is evacuated. ${ }^{1,2}$ In these cases an indwelling pleural catheter is probably a better treatment alternative. ${ }^{1,2}$

Considering this, the aim of the present study was to compare the outcome of subjects with symptomatic MPE treated with TP, either as a procedure of BSC management (subjects no longer eligible for cancer therapy) or in addition to planned or ongoing cancer therapy (hereafter called non-BSC). TP success rate, side effects (i.e., chest pain/dyscomfort, desaturation, and fever), complications, hospital days due to $\mathrm{TP}$, remaining time alive (from chest tube insertion to death), and performance status were recorded. Based on the radiologic findings presented prior to $\mathrm{TP}$, the pulmonologist in charge was also asked for a prognosis regarding the chance of successful TP.

Division of Pulmonary Medicine, Department of Medical and Health Sciences, Faculty of Health Sciences, Linköping University, Department of Respiratory Medicine UHL, Centre of Surgery and Oncology, County Council of Östergötland, Linköping, Sweden.

Accepted February 3, 2014. 


\section{Materials and Methods}

\section{Ethical considerations}

The study protocol was approved by the local Ethical Committee (Linköping, Sweden; 2011/266-31) according to the guidelines of the Helsinki Declaration.

\section{Study population}

Patients admitted for TP at the Department of Pulmonary Medicine, University Hospital in Linköping, Sweden, were consecutively included during a 1-year period. After obtained consent, TP was performed on 30 Caucasians. Approximately 6 years after the last included subject the outcome was evaluated retrospectively using patient medical records. One patient was later diagnosed with pleural effusion of benign etiology and was therefore excluded. The remaining 29 subjects had histocytologically proven MPE.

All TPs were performed in hospital according to local routines using either small-bore $(6-16 \mathrm{~F}$; mainly pig-tail catheters) or large-bore (20-28F) tubes (Portex-Smiths Medical, Dublin, $\mathrm{OH}$ ). Timing of talc insertion (as a bedside slurry of 5 grams of talc per $200 \mathrm{~mL}$ of sterile $0.9 \% \mathrm{NaCl}$ ) was determined by the attending pulmonologist, when the lung was fully or nearly fully reexpanded and drainage volume was less than $150 \mathrm{~mL}$ per 24 hours. Unless there was any other reason for further inpatient care, patients were discharged following a satisfactory post-TP chest radiograph.

\section{Assessment of outcomes}

Chest pain/discomfort (assessed using a visual analogue scale [VAS] scale scoring from 0 to 10), saturation (SAT\%), and body temperature $\left({ }^{\circ} \mathrm{C}\right)$ during chest drainage post-talc instillation, complications during hospitalization, the number of days in hospital (i.e., days with chest tube and days after $\mathrm{TP}$ required for recovery), and the remaining time alive after talc instillation were recorded. When it was considered possible to predict, the physician in charge of the TP was also asked for a prognosis regarding the chance for a successful TP before TP was performed. Successful TP was defined as not needing another ipsilateral TP at any time. Based on presented radiology (chest X-ray findings prior to TP (after evacuation of pleural fluid), i.e., whether or not the lung was fully expanded, a thickened visceral pleura and/or organized fluid were present) the predicted outcome of the planned TP for each subject was scored as either "excellent," "fair," or "poor." Functional and physical performance was assessed using the WHO score ${ }^{17}: 0=$ able to carry out all normal activity without restriction; $1=$ restricted in physically strenuous activity but ambulatory and able to carry out light work; $2=$ ambulatory and capable of all self-care but unable to carry out any work, up and about more than $50 \%$ of waking hours; 3 = capable of only limited self-care, confined to bed or chair more than $50 \%$ of waking hours; and $4=$ completely disabled, cannot carry out any self-care, totally confined to bed or chair. TP was not performed unless performance status was 3 or less.

\section{Statistical analysis}

The results are the means \pm 1 standard deviation (SD). STATISTICA (version 10; StatSoft, Tulsa, OK) was used for comparison (the $t$ test; $p<0.05$ [*], $p<0.01$ [**], and $p<0.001[* * *])$ of groups and correlations between variables. The $\chi^{2}$ test and Kolmogorov-Smirnov test were used for assessment of normal distribution.

\section{Results}

\section{Advanced lung cancer was the main cause behind TP-treated MPE}

Population characteristics are summarized in Table 1. Subjects were divided into two groups; the BSC group (no further cancer therapy planned and therefore expected survival less than 90 days) and the non-BSC group (planned or ongoing cancer therapy and therefore expected survival 90 days or more). There was no significant difference regarding age $(70 \pm 13$ years versus $70 \pm 9$ years). The BSC group comprised 10 subjects (5 males and 5 females); 7 subjects with lung cancer, 2 subjects with breast cancer, and 1 subject with tongue cancer. The non-BSC group comprised 19 subjects (4 males and 15 females); 10 subjects with lung cancer, 2 subjects with gynecologic cancer, 3 subjects with cancer in

Table 1. Characteristics of the Population Studied

\begin{tabular}{|c|c|c|c|c|}
\hline No. & Gender & Age & Type of cancer & Tube/size \\
\hline \multicolumn{5}{|c|}{ BSC management (expected survival $<90$ days) } \\
\hline 1 & M & 86 & Lung & Pig/12 \\
\hline 2 & M & 77 & Lung & Port/28 \\
\hline 3 & M & 63 & Lung & Pig/12 \\
\hline 4 & $\mathrm{~F}$ & 70 & Tongue & Port $/ 20$ \\
\hline 5 & $\mathrm{~F}$ & 50 & Lung & Port/20 \\
\hline 6 & $\mathrm{~F}$ & 61 & Breast & Port/20 \\
\hline 7 & $\mathrm{~F}$ & 52 & Breast & Port/22 \\
\hline 8 & M & 81 & Lung & Pig/14 \\
\hline 9 & M & 75 & Lung & Port $/ 20$ \\
\hline \multirow[t]{3}{*}{10} & $\mathrm{~F}$ & 82 & Lung & Pig/6 \\
\hline & $50 \%$ & $70 \pm 13$ & $70 \%$ lung cancer & $60 \%$ \\
\hline & females & & & large-bo \\
\hline
\end{tabular}

Non-BSC (planned or ongoing cancer therapy; expected survival $\geq 90$ days)

$\begin{array}{rrrcc}1 & \text { M } & 65 & \text { Lung } & \text { Port/20 } \\ 2 & \mathrm{~F} & 64 & \text { Lung } & \text { Port/16 } \\ 3 & \mathrm{~F} & 64 & \text { Lung } & \text { Port/20 } \\ 4 & \mathrm{~F} & 80 & \text { Lung } & \text { Port/20 } \\ 5 & \mathrm{~F} & 66 & \text { Lung } & \text { Pig/8 } \\ 6 & \mathrm{M} & 65 & \text { Lung } & \text { Port/22 } \\ 7 & \mathrm{~F} & 66 & \text { Lung } & \text { Port/20 } \\ 8 & \mathrm{~F} & 62 & \text { Lung } & \text { Port/20 } \\ 9 & \mathrm{~F} & 65 & \text { Lung } & \text { Port/14 } \\ 10 & \mathrm{M} & 53 & \text { Mesothelioma } & \text { Port/20 } \\ 11 & \mathrm{~F} & 84 & \text { Unknown primary } & \text { Port/20 } \\ 12 & \mathrm{~F} & 80 & \text { Urinary tract } & \text { Port/20 } \\ 13 & \mathrm{~F} & 80 & \text { Urinary tract } & \text { Port/16 } \\ 14 & \mathrm{~F} & 74 & \text { Gynecologic } & \text { Port/20 } \\ 15 & \mathrm{~F} & 70 & \text { Gynecologic } & \text { Port/20 } \\ 16 & \mathrm{~F} & 70 & \text { Kidney } & \text { Port/20 } \\ 17 & \mathrm{M} & 81 & \text { Lung } & \text { Port/16 } \\ 18 & \mathrm{~F} & 79 & \text { Breast } & \text { Port/20 } \\ 19 & \mathrm{~F} & 57 & \text { Breast } & \text { Port/20 } \\ & 79 \% & 70 \pm 9 & 53 \% \text { lung cancer } & 74 \% \\ & \text { females } & (0.99) & & \text { large-bore }\end{array}$

Data are presented as the means \pm 1 standard deviation (SD). BSC, best support of care. 
the urinary tract (including kidney cancer), 1 subject with mesothelioma, and 1 subject with an unknown primary tumor. Large-bore tube sizes $(\geq 20 \mathrm{~F})$ were more frequent in the non-BSC group.

\section{TP success and complications}

Success rate was $79 \%$ (15/19 cases) in the non-BSC group, but only $56 \%$ (5/9 evaluable cases) in the BSC group (Table 2). Overall success rate of TPs was $71 \%$ (20/28 evaluable cases). Talc pleurodesis performed with small-bore tube sizes (i.e., <20F) were successful in 5 of 9 cases $(56 \%)$, while TPs performed using large-bore tube sizes were successful in 15 of 19 evaluable cases (79\%). One patient in the BSC group died during hospitalization as a result of the TP performed
(Table 2). Three subjects were infected and another subject had a stroke, but all 4 subjects recovered and were eventually discharged (Table 2). Complication frequency was 17\% (5/ 29 subjects).

\section{Poorer performance status and shorter survival characterized the BSC group}

The performance status of subjects in the BSC group was significantly poorer $(2.5 \pm 0.5)$ than the performance status of non-BSC subjects $(1.5 \pm 0.7 ; p=0.0006$; Table 2$)$. Survival time in the BSC group after TP was significantly shorter than in the non-BSC group; $44 \pm 26$ days and $410 \pm 455$ days, respectively ( $p=0.003$; Table 2$)$. The survival time agreed well with life expectancy, thus, 8 of 9 evaluable BSC subjects

Table 2. The Outcome of the Pleurodesis Performed

\begin{tabular}{|c|c|c|c|c|c|c|}
\hline No. & $\begin{array}{l}\text { Successful } \\
\text { pleurodesis }\end{array}$ & $\begin{array}{l}\text { Performance } \\
\text { status }\end{array}$ & $\begin{array}{l}\text { Survival } \\
\text { (days) }\end{array}$ & $\begin{array}{c}\text { Days in hospital } \\
\text { (days) }\end{array}$ & $\begin{array}{c}\text { Days in } \\
\text { hospital/survival } \\
(\%)\end{array}$ & $\begin{array}{l}\text { Physician's } \\
\text { assessment }\end{array}$ \\
\hline \multicolumn{7}{|c|}{ BSC management (expected survival $<90$ days) } \\
\hline 1 & No & 3 & 25 & 16 & 64 & Not predictable \\
\hline 2 & No & 3 & 51 & 14 & 27 & Not predictable \\
\hline 3 & $\mathrm{No}^{\mathrm{a}, \mathrm{b}}$ & 3 & 16 & 16 & 100 & Not predictable \\
\hline 4 & Yes & 3 & 39 & 14 & 36 & Excellent \\
\hline 5 & Yes & 2 & 36 & 14 & 39 & Not predictable \\
\hline 6 & No & 2 & 17 & 9 & 53 & Fair \\
\hline 7 & Unknown & 2 & Unknown & 7 & Unknown & Excellent \\
\hline 8 & Yes $^{\mathrm{c}}$ & 2 & 63 & 14 & 22 & Not predictable \\
\hline 9 & Yes & 2 & 97 & 7 & 7 & Not predictable \\
\hline \multirow[t]{2}{*}{10} & Yes $^{\mathrm{d}}$ & 3 & 52 & 19 & 32 & Excellent \\
\hline & $56 \%$ successful & $2.5 \pm 0.5$ & $44 \pm 26$ & $13 \pm 4$ & $42 \pm 27$ & $40 \%$ Fair/excellent \\
\hline \multicolumn{7}{|c|}{ Non-BSC (planned or ongoing cancer therapy; expected survival $\geq 90$ days) } \\
\hline 1 & Yes $^{\mathrm{e}}$ & 1 & Unknown & 9 & Unknown & Excellent \\
\hline 2 & $\mathrm{Yes}^{\mathrm{c}}$ & 2 & 153 & 10 & 6 & Excellent \\
\hline 3 & Yes & 0 & 388 & 16 & 4 & Excellent \\
\hline 4 & Yes & 1 & 453 & 2 & 0.4 & Excellent \\
\hline 5 & $\mathrm{No}^{\mathrm{f}}$ & 1 & 93 & 11 & 12 & Not predictable \\
\hline 6 & $\mathrm{Yes}^{\mathrm{f}}$ & 2 & 122 & 11 & 9 & Fair \\
\hline 7 & Yes & 1 & 298 & 7 & 2 & Not predictable \\
\hline 8 & Yes & 2 & 400 & 7 & 2 & Not predictable \\
\hline 9 & $\mathrm{Yes}^{\mathrm{g}}$ & 2 & 151 & 7 & 5 & Excellent \\
\hline 10 & No & 2 & 936 & 3 & 0.3 & Excellent \\
\hline 11 & Yes & 1 & 632 & 8 & 1 & Excellent \\
\hline 12 & No & 2 & 384 & 15 & 4 & Not predictable \\
\hline 13 & $\mathrm{Yes}^{\mathrm{b}}$ & 2 & 321 & 7 & 2 & Fair \\
\hline 14 & Yes & 2 & 362 & 6 & 2 & Fair \\
\hline 15 & Yes & 3 & 102 & 17 & 17 & Not predictable \\
\hline 16 & Yes & 1 & 149 & 6 & 4 & Excellent \\
\hline 17 & No & 1 & 115 & 6 & 5 & Excellent \\
\hline 18 & Yes & 2 & 2021 & 7 & 0.3 & Excellent \\
\hline \multirow[t]{2}{*}{19} & Yes & 1 & Unknown & 8 & 3 & Excellent \\
\hline & $79 \%$ successful & $1.5 \pm 0.7(0.0006)$ & $410 \pm 455(0.003)$ & $9 \pm 4(0.009)$ & $4 \pm 4(0.003)$ & $74 \%$ Fair/excellent \\
\hline
\end{tabular}

Data are presented as the means $\pm 1 \mathrm{SD}$.

${ }^{a}$ This patient died during hospitalization (pleurodesis performed with reduced amount of talc).

${ }^{\mathrm{b}}$ Only $3 \mathrm{~g}$ talc was given.

${ }^{\mathrm{c}}$ These two patients displayed a typical clinic for pneumonia and responded well to antibiotic treatment but the diagnosis were not microbiologically or radiologically verified.

${ }^{\mathrm{d}}$ Mepacrine chloride was used because of a very thin pleural catheter.

${ }^{\mathrm{e}}$ This patient was diagnosed and treated successfully for empyema, which was microbiologically not verified.

${ }^{\mathrm{f}}$ Partly trapped lung.

${ }^{\mathrm{g}}$ This patient was diagnosed with a stroke the day after performed procedure, but recovered without significant sequel.

SD, standard deviation; MPE, malignant pleural effusion; PS, performance status; BSC, best support of care management; TP, talc pleurodesis. 
were dead within 90 days and all eligible non-BSC subjects $(n=18)$ were alive after 90 days or more.

\section{BSC subjects spent more time at hospital due to TP}

Subjects in the non-BSC group spent $9 \pm 4$ days in the hospital, corresponding to $4 \% \pm 4 \%$ of their remaining time alive (Table 2). In contrast, subjects scheduled for BSC spent $13 \pm 4$ days $(p=0.009)$ in hospital, and hospitalization time constituted a major part of their remaining time alive ( $42 \% \pm 27 \% ; p=0.003$; Table 2$)$. Accounting only for lung cancer subjects, the same comparisons were significantly different as well $(p<0.01$ and $p<0.03)$.

\section{The pulmonologist's assessment of radiology was a poor predictor of successful TP}

The TP outcome was known in 28 of 29 cases. Only 18 of these $(64 \%)$ were regarded as possible to predict (Table 2). Notably, $67 \%$ of the TPs of the BSC group were categorized as "not predictable" (6/9 subjects).

Correspondingly, only $26 \%$ (5/19 subjects) of the nonBSC subjects was "not predictable." Overall, in 11 of 28 planned TPs (39\%) the physician considered the TP as not possible to predict. All predictable TPs $(n=17)$ were expected to have a good chance for a success ("excellent" or "fair"). Of these the clinician's assessment of successful TP was correct in 14 cases (2 BSC subjects and 12 non-BSC subjects) of 17 cases $(82 \%)$. However, for all eligible cases the clinician was correct about a successful TP only in 14 of 28 subjects $(50 \%)$.

\section{Poor performance status and short survival of lung cancer subjects were associated with a long hospitalization for TP}

Correlation studies of groups (i.e., type of cancer [all cancer types, lung cancer only and cancer of other origin than the lung] and planned management in these groups [BSC and non-BSC]) were performed comparing subjects regarding the following variables: age, performance status, number of hospitalization days, and survival. Performance status and days of hospitalization $(r=0.4345, p=0.024)$ and survival time and number of hospitalizations days $(r=-0.4163$, $p=0.031)$ correlated for all included subjects. Similarly, survival time and length of hospitalization $(r=-0.6407$, $p=0.007)$ and performance status and survival time $(r=$ $-0.6011, p=0.014)$ correlated for lung cancer subjects. A significant correlation was also observed in the BSC group between performance status and number of hospitalization days $(r=0.6950, p=0.038)$.

\section{Lung cancer subjects desaturated more than non-lung cancer subjects did after TP}

Side effects of TP (chest pain, desaturation, and a rise of body temperature) of all subjects included are shown in Figure 1. All variables were significantly changed versus the initial assessment at day 2, and were normalized within a couple of days. No difference was found between BSC versus non-BSC and small-bore tube size versus large-bore tube size. However, subjects with lung cancer, compared to those with cancer of other origin, displayed significantly lower saturation before and after TP (data not presented).

\section{Discussion}

The aim of the present study was to compare the outcome of subjects with symptomatic MPE treated with TP, either as a procedure of BSC management (subjects no longer eligible for cancer therapy) or in addition to planned or ongoing cancer therapy (non-BSC). The present study defines a group of MPE subjects not suitable for TP in terms of poor chance for successful TP and long time spent at hospital as days and hospitalization time relative to survival post-TP. These subjects had poor performance status, making them no longer eligible for chemotherapy, and, as a consequence, scheduled for TP as part of BSC management. According to previous reports, time spent at hospital during TP is usually 4-6 days. ${ }^{4,5}$ In the present study BSC subjects stayed $13 \pm 4$ days in the hospital and non-BSC subjects $9 \pm 4$ days $(p<0.01)$. Due to very short survival, hospitalization time became a major part of the remaining time alive of BSC subjects, $42 \% \pm 27 \%$, compared to $4 \% \pm 4 \%$ for non-BSC subjects $(p<0.01)$. Unlike many other studies, which assess TP success at approximately 30 days post-TP, in the present study a successful TP success was defined more correctly as not needing another ipsilateral TP at any time after the TP performed. According to this definition, overall success rate of TPs in the present study was well in line with previous reports (approximately 70\%-80\%). ${ }^{9,10,18}$ In contrast, TPs performed on BSC subjects was successful in every second case. Considering the very long time spent in the hospital by many of the BSC subjects, such a low success rate is unsatisfactory.

Performance status was significantly poorer in the BSC group, but most subjects (6/9 subjects) lived more than 30 days post-TP, which is a life expectancy considered as appropriate to perform TP. ${ }^{2,9,14}$ The outcome of TP depends very much on the aggressiveness of the tumor causing MPE and the intention to treat, BSC or cancer therapy. One might therefore question whether this relatively small cohort of MPE subjects at a single center is representative. However, similar to larger cohort studies, ${ }^{1,2,9-11}$ the proportions of subjects with lung cancer and BSC subjects were two thirds and one third, respectively. In recent studies improvement of quality of life is an important outcome of TP.,19,20 This variable of TP success was not assessed in the present study, which is a weakness.

Complication frequency in the present study was higher than what is previously reported in the literature (1\%$10 \%) .{ }^{17,18}$ This observation may indicate that the subjects included were less suitable for TP than those participating in similar studies. It should be pointed out however that MPE/TP studies define and describe the complication rate very differently, making comparisons of studies rather difficult. As in the present study, some researchers choose to distinguish serious complications from the more common and expected side effects. Regarding the latter, lung cancer subjects exhibited significantly lower saturation pre- and post-TP than non-lung cancer subjects did, which most likely is because of concomitant lung disease (lung tumor and chronic obstructive pulmonary disease) involving the lung parenchyma.

In the present study the ability of the responsible pulmonologist to assess the chance for successful TP was studied, as 

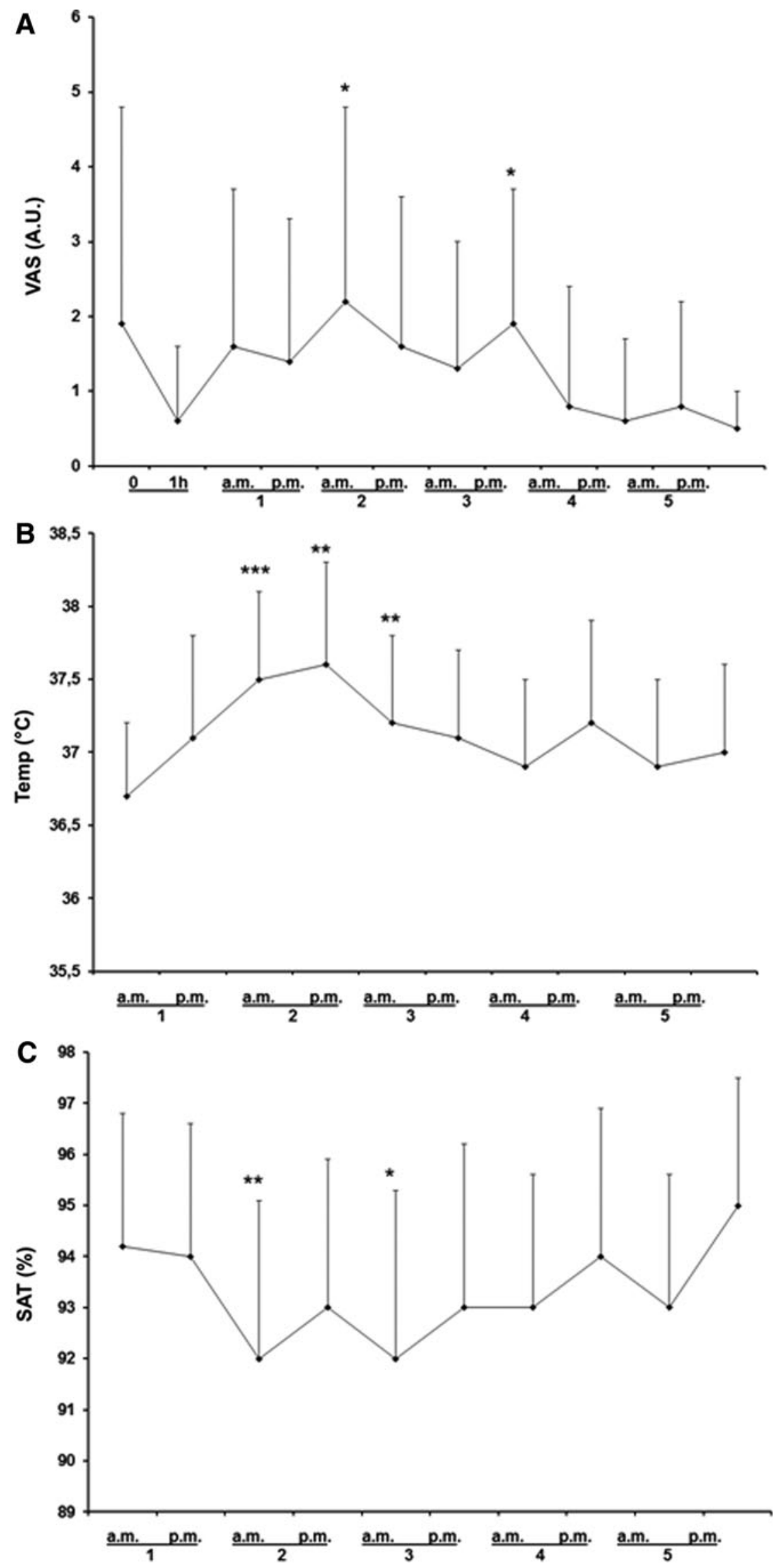

FIG. 1. Side effects during chest drainage post-TP, i.e., chest pain (A), fever $(\mathbf{B})$, and desaturation $(\mathbf{C})$ for the total number of patients evaluated. Values are the means \pm 1 SD. Significant differences versus the initial assessment are indicated as follows: ${ }^{*} p<0.05, * * p<0.01$, and $* * * p<0.001$. TP, talc pleurodesis; SD, standard deviation; SAT, saturation; VAS, visual analogue scale. 
far as we know, for the first time. Naturally, none of the TPs performed was defined as having a "poor" chance for success (in such a case TP should never be considered). Notably, more than two-thirds of planned TPs were considered by the physician in charge as not possible to predict. This issue was a dominating feature of the BSC group, which might suggest that the physician in charge, indeed, had some doubts regarding the value of the TP planned. The decision to proceed to TP was in all cases made by an experienced senior pulmonologist and in most cases also preceded by a consensus statement of two or more senior consultants. In other studies attempts have been made to predict TP outcome on the basis of analysis of different pleural fluid parameters. ${ }^{10,15,16}$ Since only every second TP were correctly predicted as successful, it seems that even experienced pulmonologists would need the support of reliable predictive tests.

The present study is relatively small and done at only one center. Thus, local treatment customs and the opinions of individual physicians when to proceed to TP (or not) might have some impact on the results presented. Even though TP seems less favorable among BSC subjects, suggesting that repeated thoracocentesis or indwelling pleural catheters would be better treatment options, such comparison of different therapies was beyond the scope of the present study. TP is generally considered as a cost-effective procedure, but naturally, this is only if time of hospitalization is kept short. ${ }^{9,14,21}$

\section{Conclusions}

Lessons learned from the present study are that TP should probably not be considered as a first choice of treatment for MPE patients planned for BSC management. The present study also supports the concept that the physician's assessment of clinic and radiology is inadequate in most cases for the prediction of the TP outcome.

\section{Acknowledgments}

This work was supported by grants to HLP from the County Council of Östergötland (ALF), Sweden.

The authors acknowledge the invaluable assistance of the nurses at the ward of the department of Pulmonary Medicine and the contribution of the study subjects.

A.W. collected some data, analyzed all data, and wrote the manuscript. H.E. planned and conducted the study, collected most data, and analyzed some data, while H.L.P. analyzed all data and wrote the manuscript. All authors have given their final approval of the version submitted. This study was performed at the Divisions of Pulmonary Medicine, Linköping University, Sweden.

\section{Author Disclosure Statement}

No competing financial interests exist.

\section{References}

1. Tan C, Sedrakyan A, Browne J, Swift S, Treasure T: The evidence on the effectiveness of management for malignant pleural effusion: A systematic review. Eur J Cardiothorac Surg 2006;29:829-838.

2. Roberts ME, Neville E, Berrisford RG, Antunes G, Ali NJ; BTS Pleural Disease Guideline Group: Management of a malignant pleural effusion: British Thoracic Society Pleural
Disease Guideline 2010. Thorax 2010;65(Suppl 2):ii32_ ii40.

3. Shaw P, Agarwal R: Pleurodesis for malignant pleural effusions. Cochrane Database Syst Rev 2004;1:CD002916.

4. Reddy C, Ernst A, Lamb C, Feller-Kopman D: Rapid pleurodesis for malignant pleural effusions: A pilot study. Chest 2011;139:1419-1423.

5. Davies HE, Mishra EK, Kahan BC, Wrightson JM, Stanton AE, Guhan A, Davies CW, Grayez J, Harrison R, Prasad A, Crosthwaite N, Lee YC, Davies RJ, Miller RF, Rahman NM: Effect of an indwelling pleural catheter vs chest tube and talc pleurodesis for relieving dyspnea in patients with malignant pleural effusion: The TIME2 randomized controlled trial. Jama 2012;307:2383-2399.

6. Kolschmann S, Ballin A, Juergeuns UR, Rohde G, Gessner C, Hammerschmidt S, Wirtz H, Gillissen A: Talc pleurodesis in malignant effusions. Pneumologie 2006;60:89-95.

7. Rodriquez-Panadero F, Romero-Romero B: Management of pleural effusions. Curr Opin Pulm Med 2011;17:269273.

8. Sahn SA: Talc should be used for pleurodesis. Am J Respir Crit Care Med 2000;162:2023-2024.

9. Ong KC, Indumathi V, Raghuram J, Ong YY: A comparative study of pleurodesis using talc slurry and bleomycin in the management of malignant pleural effusions. Respirology 2000;5:99-103.

10. Ozyurtkan MO, Balci AE, Cakmak M: Predictors of mortality within three months in the patients with malignant pleural effusion. Eur J Intern Med 2010;21:30-34.

11. Musani AI, Haas AR, Seijo L, Wilby M, Sterman DH: Outpatient management of malignant pleural effusions with small-bore, tunneled pleural catheters. Respiration 2004;71: 559-566.

12. Fujita A, Takabatake H, Tagaki S, Sekine K: Combination chemotherapy in patients with malignant pleural effusions from non-small cell lung cancer. Chest 2001;119:340-343.

13. Niho S, Kubota K, Yoh K, Walter MJ, Borys NJ, Lupton JM, Boehme C: Clinical outcome of chemoradiation therapy in patients with limited-disease small cell lung cancer with ipsilateral pleural effusion. J Thorac Oncol 2008;7: 723-727.

14. Lynch TJ Jr. Management of malignant pleural effusions. Chest 1993;103(4 Suppl):385S-389S.

15. Yildirim H, Metintas M, Ak G, Metintas S, Erginel S: Predictors of talc pleurodesis in patients with malignant pleural effusions. Lung Cancer 2008;62:139-144.

16. Martinez-Moragon E, Aparicio J, Sanchis J, Menéndez R, Cruz Rogado M, Sanchis F: Malignant pleural effusion: Prognostic factors for survival and response to chemical pleurodesis in a series of 120 cases. Respiration 1998;65: 108-113.

17. World Health Organisation: WHO Handbook for Reporting Results of Cancer Treatment. Geneva: WHO Offset Publication 1979; No 48.

18. Terra RM, Teixeira LR, Bibas BJ, Pego-Fernandes PM, Vargas FS, Jatene FB: Effectiveness and safety of outpatient pleurodesis in patients with recurrent malignant pleural effusion and low performance status. Clinics (Sao Paulo) 2011;66:211-216.

19. Basso SM, Mazza F, Marzano B, Santeufemia DA, Chiara GB, Lumachi F: Improved quality of life in patients with malignant pleural effusion following videoassisted thoracoscopic talc pleurodesis. Preliminary results. Anticancer Res 2012;32:5131-5134. 
20. Dresler CM, Olak J, Herndon JE 2nd, Richards WG, Scalzetti E, Fleishman SB, Kernstine KH, Demmy T, Jablons DM, Kohman L, Daniel TM, Haasler GB, Sugarbaker DJ; Cooperative Groups Cancer and Leukemia Group B; Eastern Cooperative Oncology Group; North Central Cooperative Oncology Group; Radiation Therapy Oncology Group: Cooperative Groups Cancer and Leukemia Group B; Estern Cooperative Oncology Group; North Central Cooperative Oncology Group; Radiation Therapy Oncology Group. Phase III intergroup study of talc poudrage vs talc slurry sclerosis for malignant pleural effusion. Chest 2005;127:909-915.

21. Aelony Y: Cost-effective pleurodesis. Chest 1998;113: 1731-1732.
Address correspondence to: H. Lennart Persson, MD, PhD Division of Pulmonary Medicine Department of Medical and Health Sciences Faculty of Health Sciences Linköping University Department of Respiratory Medicine UHL Centre of Surgery and Oncology County Council of Östergötland Linköping SE-581 85 Linköping Sweden

E-mail: Lennart.Persson@liu.se 